\title{
Research on Supply Chain Management and Talent Assurance of Emergency Logistics Personnel under Public Health Emergencies
}

\author{
Changli Lu*, Min Chen \\ School of Economics and Management, Shanghai Maritime University, Shanghai, China \\ Email: *cheery18521319257@163.com
}

How to cite this paper: Lu, C. L., \& Chen, M. (2021). Research on Supply Chain Management and Talent Assurance of Emergency Logistics Personnel under Public Health Emergencies. American Journal of Industrial and Business Management, 11, 60-75.

https://doi.org/10.4236/ajibm.2021.111005

Received: December 18, 2020

Accepted: January 18, 2021

Published: January 21, 2021

Copyright $\odot 2021$ by author(s) and Scientific Research Publishing Inc. This work is licensed under the Creative Commons Attribution International License (CC BY 4.0).

http://creativecommons.org/licenses/by/4.0/

\begin{abstract}
Public health emergencies, if not dealt with in a timely manner, can result in more serious impacts on a larger scale, and solving public health emergencies requires emergency logistics as a channel to provide materials. The focus on emergency logistics has led to the development of the emergency logistics industry, but the requirements for emergency logistics enterprises are also gradually increasing. As the core element of enterprise development, it is crucial for the enterprise to manage the talent issues well. The current emergency logistics talent problems for the development of emergency logistics industry under public health emergencies have created a major constraint, which in turn affects the effective resolution of public health emergencies. In this paper, we mainly discuss two aspects of emergency logistics companies' talent supply chain management and talent protection under public health emergencies, analyze emergency logistics companies' relevant data, study the reasons why the development of emergency logistics companies is constrained, analyze the problems of talent supply chain management and talent protection respectively, and make suggestions for the problems, which are of great importance to the solution of public health emergencies. Very important significance.
\end{abstract}

\section{Keywords}

Public Health Emergencies, Emergency Logistics, Talent Supply Chain Management, Talent Security

\section{Research Background}

A public health emergency is a sudden public health event that may or has caused serious harm to society and requires emergency measures, such as a major epi- 
demic of infectious diseases, mass unexplained diseases, and other events that will seriously affect public health and life safety. The characteristics include: first, with the rapid development of the economy, public health emergencies occur more frequently; second, the hazard is greater, as the occurrence of public health emergencies usually has a serious impact on citizens' lives and social stability; third, they must be dealt with in a timely manner, as public health emergencies occur suddenly, without warning, and cannot be dealt with according to the usual procedures, and the relevant departments must increase cooperation efforts to respond quickly (Chen, 2020). On the premise of public health emergencies, the emergency logistics industry was then created and emergency logistics enterprises developed, but the development time is too short for emergency logistics enterprises to reach the required standard for responding to public health emergencies. The management of emergency logistics enterprises needs multi-faceted coordination, and this paper mainly analyzes two aspects of emergency logistics talent supply chain and talent security. Talent supply chain and talent security are both crucial for the future development of emergency logistics enterprises and for solving public health emergencies. For the talent supply chain, you need to do a good job in the supply of talent, talent training, talent planning, talent incentive planning and development, and then help emergency logistics enterprises to retain the core backbone of the talent, and promote the rapid development of emergency logistics enterprises; for talent security, the introduction, training talent is very important, to provide personnel satisfaction talent security will also promote the development of emergency logistics enterprises.

Firstly, this paper elaborates the theories and research status of emergency logistics, talent supply chain and talent protection, then analyzes the relevant data of emergency logistics companies in recent years, and lists the problems of emergency logistics companies in talent supply chain and talent protection under public health emergencies.

\section{Theoretical Foundations and Literature Review}

\subsection{Theoretical Basis of Emergency Logistics}

Emergency logistics, originally developed along with military logistics, integrates logistics management, emergency management, and storage management into one discipline. Its construction is of great significance to the stability and development of the country and the region. Emergency logistics is one kind of logistics, but emergency logistics is a special kind of logistics. Emergency logistics refers to the emergency situation such as sudden public health events or sudden natural disasters, to provide emergency supplies, and to achieve maximum time efficiency and minimize disaster losses of special logistics activities. In addition to the unpredictability, multi-subjectivity, timeliness, urgency and other characteristics, there are the following special features, first, emergency logistics is a kind of emergency organization social security activities by the government and 
the community, but also in public health emergencies and other emergencies must be taken; second, the system management of emergency logistics needs unified command and division of labor; third, the emergency logistics is a kind of emergency organization social security activities, but also in public health emergencies and other emergencies must be taken; third, the emergency logistics is a kind of emergency organization social security activities. The purpose of emergency logistics activities is to minimize disaster losses and impacts; fourth, for emergency logistics, time is of the essence ( $\mathrm{Du}, 2016)$.

\subsection{Theoretical Foundations of Supply Chain Management and Talent Supply Chain Management}

\subsubsection{Theoretical Foundations of Supply Chain Management}

The commonly accepted definition of supply chain management is that it is the management of activities that need to be strengthened in three areas when operating a supply chain, and these three areas are: first, to shorten the liquidity time; second, to reduce the level of risk that a company may encounter in its daily operations; and third, to increase earnings and projected revenue for the company. Through the strengthening of these three aspects to achieve the optimization of supply chain operations, from the beginning of the entire supply chain procurement to the final demand of customers, at the lowest cost, the suppliers, manufacturers, warehouses, distribution centers and distributors are organized rationally, and work together to carry out the entire management process of product manufacturing, trans-shipment, distribution and sales, in order to ensure that the best products, at the best price, and the fastest delivery to the needy customer hands.

The purpose of supply chain management is to divide and optimize the entire supply chain, grasp the flow of goods, information and capital of customers, and reduce logistics and inventory costs to the maximum extent possible on the premise of satisfying customer needs. In short, the right product that the customer needs, in the right time, in the quantity that the customer needs, in the satisfactory quality and condition, to the right place provided by the customer, and to achieve the cost optimization of the whole process. Therefore, supply chain management takes integrated and synchronized production planning as a guideline and relies on various advanced technologies, especially web-based technologies, to manage customer needs, make production plans, implement production plans, supply products that correspond to the needs, deliver logistics, and deliver orders.

\subsubsection{Talent Supply Chain Management Theory}

Talent supply chain management is developed on the basis of supply chain management theory, and there are many similarities between the two for an optimal management of talent.

The procurement part of supply chain management corresponds to the external supply of HR supply chain management, the inventory management of supply 
chain management corresponds to the talent pool of HR supply chain management, the distribution management of supply chain management corresponds to the internal allocation of HR supply chain management, the information technology of supply chain management corresponds to the information system of HR supply chain management, the cost optimization and performance management of supply chain management corresponds to the talent pool of HR supply chain management. Performance evaluation, risk management in supply chain management corresponds to risk management in talent supply chain management.

Talent supply chain management is based on enterprise development strategy and talent management implementation, and analyzes the whole process of talent supply chain management from the four dimensions of "flexible standard talent inventory, dynamic short-term talent planning, ROI maximizing talent training, and no time difference talent supply" (Chen, 2017).

The dynamic short-term talent planning refers to the flexible supply of talent needed by the company under the business environment that will change at any time, as well as the close integration with the overall strategy of the company that may change at any time; the flexible standard talent inventory refers to the understanding of the total amount of talent, the utilization rate of talent and the quality of talent on the premise of understanding, through the entire company throughout the development strategy. Make appropriate talent planning, reserve and training development strategies to improve the overall talent management efficiency; Timeless talent supply emphasizes that, as long as there are talent gaps in the business, talent supply chain management can immediately provide the right amount of high-quality talent that the company needs; "ROI maximization" emphasizes the focus on input-output and return on investment. It advocates the establishment of a talent development mechanism within the organization, including a talent selection system and a talent flow supply system, and the development of training activities in line with corporate development.

\subsection{Theoretical Basis of Talent Security}

\subsubsection{Human Capital Theory}

Human capital refers to the skills and knowledge acquired by workers through practice, training, health care, and other investments. Before the formation of human capital theory, classical economists generally calculated the size of human capital from the perspective of population size. Now, with the socio-economic development, human capital is in a stage of gradual development and improvement. At this stage, the development of human capital in the academic world is mainly summarized in three stages: first, the concept of human capital is proposed, that is, the concept of human as capital; second, the concept of human capital is defined, and the specific contents of human investment and its impact on economic growth are elaborated; third, the concept of human capital is developed, and human capital is proven to play a role in issues such as income dis- 
tribution and the labor market (Xue, 2015).

Understanding human capital theory is the basis for the study of talent security. After a comprehensive scientific grasp of the origin and formation process of human capital theory and its impact on social enterprises, including emergency logistics enterprises, and understanding the correlation between human capital and economic growth in theory, and measuring the strength of these correlations in empirical terms, only then can we truly study the impact of talent security on emergency logistics enterprises.

\subsubsection{Motivation Theory}

This discussion will focus on the two-factor theory. The two-factor theory was developed by the American behaviorist Frederick Herzberg, also known as the health care theory. In the 1950s, Herzberg and his assistant conducted a survey on job satisfaction in the U.S. The questions asked were: What factors in the workplace increase job satisfaction and what factors lead to feelings of dissatisfaction? Hertzberg collated the responses and found that the factors that brought satisfaction to employees at work were those related to the job itself, while those that brought dissatisfaction were external factors outside of the job, but also related to the job. Herzberg refers to these two types of factors as motivational factors and health care factors, respectively. Specifically, health care factors are external factors, including salary, status, working environment, etc., which can only reduce dissatisfaction, but not bring satisfaction to employees; motivational factors are internal factors, including the sense of achievement, responsibility, expected development, etc., which can improve employee satisfaction and motivate employees to work enthusiastically.

The two-factor theory emphasizes that not all of an employee's needs at work are met in order to bring about an increase in job satisfaction, but only when those intrinsic needs related to the job itself are met can the employee's job satisfaction increase (Xu, 2011).

\subsection{Literature Review}

\subsubsection{Current Research on Emergency Logistics}

Ou et al. (2004) proposed the specific meaning of emergency logistics and pointed out that emergency logistics is logistics activities aimed at reducing the damage to people's lives and material property in emergency situations such as public health emergencies and sudden natural disasters. Nachtmann \& Pohl (2013) proposed a value-focused thinking principle for assessing transportation preparedness in emergency action plans. Chen \& Hua (2015) explored the entire process of emergency event continuity based on the perspective that social resources can be effectively integrated, and concluded that emergency logistics virtual consortium and Alfredo et al. (2016) explored the importance of the state of coordination between different actors in emergency logistics, based on the importance of emergency logistics in the context of uncertain multimodal environments, multi-cycles and multi Two stochastic mixed-integer planning models 
for integrating and coordinating facility location, transportation, and fleet size under multiple conditions, such as materials, in order to save resources and improve service efficiency. Li et al. (2017) based on the technical issues regarding navigation and the development trend of navigation and positioning timing systems that arise in emergency logistics activities, proposed the use of Navigation technology needs to urgently overcome technical challenges. Based on the Nepal earthquake in 2015, Dubey et al. (2018) argue that the use of distributed data centers in logistics with cloud-based collaborative processing can effectively mitigate disaster situations, and propose the use of logistics information systems to provide links between relief data centers or organizations for the purpose of sharing information in different locations.

\subsubsection{Current Research on Supply Chain Management and Talent Supply Chain Management}

1) Supply Chain Management Research Status

In the 1990s, supply chain management evolved towards synchronization, collaborative innovation, and optimization. David Hall believes that more optimized supply chain management can lead to new market segments, new product developments, and new distribution channels with higher satisfaction levels, as well as increased customer satisfaction with after-sales service, consumer satisfaction, lower inventory costs, and lower unit production costs. In a 1997 study of supply chain management conducted by PRTM Corporation, it was found that the implementation of supply chain management can reduce total costs and shorten order lead times.

In the 21st century, with the rapid development of computer information technology, supply chain management combines these advanced science and technology to revamp the entire supply chain management process, implement e-commerce, and enable companies to achieve the goal of maximizing profits and consumer satisfaction.

2) Current Research on Talent Supply Chain Management

Peter Cappelli, a professor at the Wharton School of Management in 2008, pioneered the application of the supply chain management model to human resources management by developing a talent supply chain management model that meets the strategic development needs of companies. In 2010, Fellows, DiBoris, and Nitin, R., were the first to propose the use of external recruiting to address the impact of the external business environment on a company's own development, as well as the use of action-learning programs to promote the emergent needs of talent. Grusberg and Nitin. In 2011, Mr. Xu Feng studied the talent supply chain management process from the perspective of talent inventory, and proposed that talent supply chain management can be collectivized and synchronized to meet the talent needs of an enterprise. In 2013, Gao Zhongfei analyzed the talent supply chain partners and found a way to improve the value of talent in the internal flow process, suggesting that the talent supply chain must introduce a "cooperation, prediction and replenishment" model. 


\subsubsection{Current Research on Talent Security}

This paper collects the research of different scholars on talent security from different perspectives.

Ma Hongqi and Wang Ren proposed a new understanding of human capital formation theory based on the two stages of academic understanding of human capital formation theory, the first stage being the influence of individual decisions and efforts on human capital, and the second stage being the influence of economic development prerequisites on human capital formation. They argue that all human capital discussed at this stage is at the supply level, but in this case the human capital discussed is only potential human capital, and potential human capital must be discussed in the context of competition and incentives in conjunction with economic premises before it can be considered as real human capital. Based on the natural and social properties of human capital, they examine the formation of human capital from different levels, such as micro and macro, and essentially distinguish human capital from real human capital.

Taking Caofeidian Industrial Zone as an object of research, Wang Jianqiang predicts the demand for talents from its advantages and disadvantages. $\mathrm{He}$ pointed out that Caofeidian Industrial Zone will be more attractive to talents given its advantages in location, industry, resources and timing, but it will also have an impact on talent attraction if the national preferential policies are not comprehensive enough, the living environment is not pleasant enough, and the competitiveness of talents is not strong enough. Wang forecasted the demand for talents in Caofeidian from both structural and quantitative indicators.

Wang Yunhong pointed out that there are four influential factors that must be considered in building a highly skilled personnel training guarantee system: first, training conditions; second, training organizations; third, training funds; and fourth, the employment system. He pointed out that in order to ensure that highly skilled talents are not lost, it is necessary to increase financial investment, social mechanisms and the enterprise's own funding efforts. In addition, the insurance and welfare treatment of talents should also be strengthened.

\section{Current Situation of Emergency Logistics Companies}

The occurrence of public emergencies places high demands and needs on emergency logistics, hoping to mitigate the impact and loss of public health emergencies on society by maximizing time efficiency and minimizing disaster losses. Emergency logistics is in urgent need of effective management and development, so emergency logistics companies are also developing along with this trend.

As shown in Figure 1 of the data, although the number of new emergency logistics enterprises per year was on the rise from 2011 to 2018, it increased from more than 1812 to 5878 during the 8-year period, achieving an increase of only 4066 enterprises, a growth rate of $224 \%$. And with the outbreak of public health emergencies, in 2019 and 2020, there was an explosive growth of emergency logistics enterprises, with the number of new emergency logistics enterprises reaching 14,059 in 2019 and 13,800 in 2020, for 2011, achieving an increase of 
12,247 enterprises and 11,988 enterprises, with growth rates of $675 \%$ and $661 \%$, respectively.

The data in Figure 2 shows that although the number of new emergency logistics enterprises with registered capital of 1 million yuan per year from 2011 to 2018 is on the increase, but the growth rate is slow, only from 782 to 2029 in 8 years, but due to the outbreak of health emergencies, in 2019, the number of emergency logistics enterprises with registered capital of 1 million yuan will reach 9032. And in 2020, the number of emergency logistics companies with a registered capital of 1 million yuan is 8915 .

The data in Figure 1 and Figure 2 indicate that, with the occurrence of public health emergencies, the emergency logistics industry has developed, the number of emergency logistics enterprises has also increased dramatically, although the number of emergency logistics enterprises can be added to a certain extent, effectively mitigate the impact of public health emergencies, but to greater efficiency to reduce the losses caused by public health emergencies, it is necessary to strengthen the management of emergency logistics enterprises. The increase in the number of emergency logistics enterprises has also increased the demand for the management of emergency logistics enterprises, and for the management

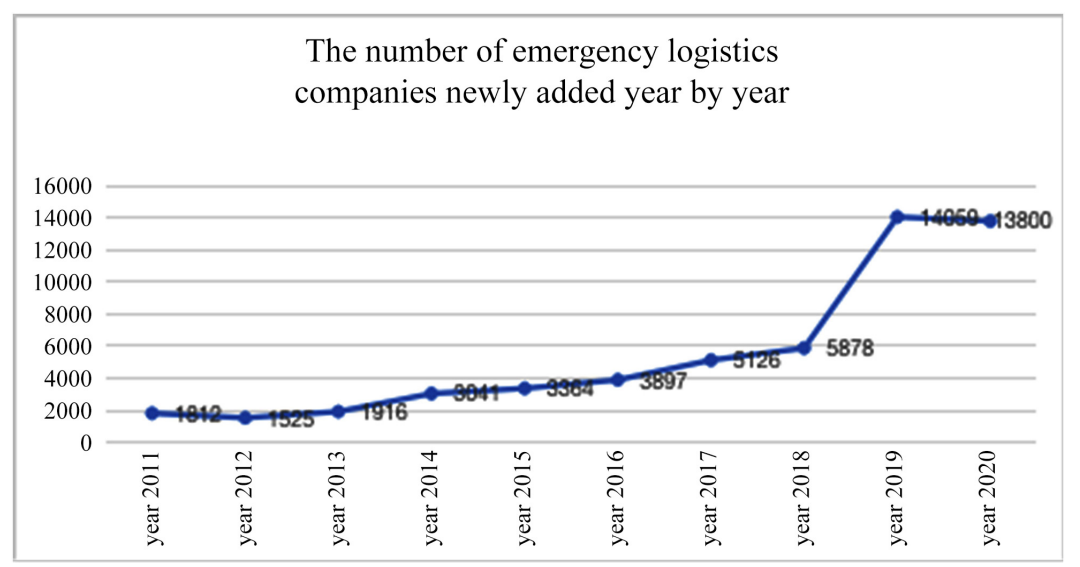

Figure 1. Number of new emergency logistics companies per year, 2011-2020. Data source: Echatel's official website (https://www.qichamao.com/trade/q3116?o=2).

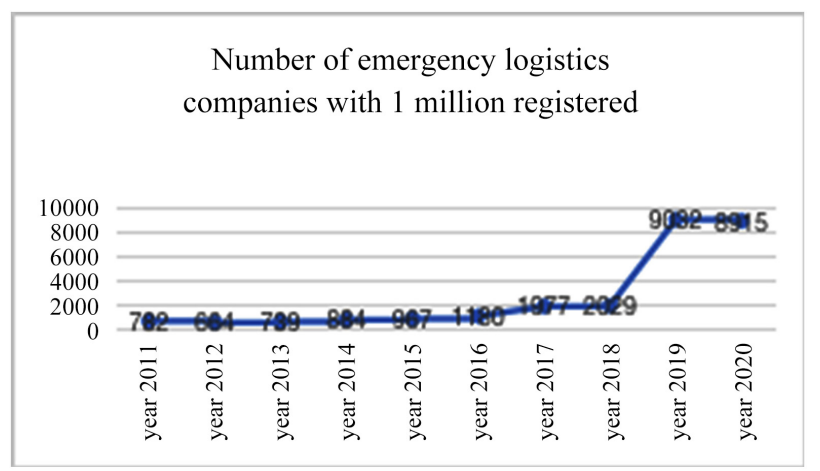

Figure 2. Number of emergency logistics enterprises with registered capital of RMB 1 million per year, 2011-2020. Data source: Echatel's official website (https://www.qichamao.com/trade/q3116?o=2). 
of emergency logistics enterprises, the supply chain management of emergency logistics personnel and talent security issues cannot be ignored.

\section{Problem Analysis of Supply Chain Management and Talent Security of Emergency Logistics Personnel in Case of Public Health Emergencies}

\subsection{Emerging Issues in Supply Chain Management for Emergency Logistics Professionals}

Although the country has increased its management and investment in emergency logistics after public health emergencies, and over the years, emergency logistics has also formed a relatively complete set of human resources management system with its own rhythm and plan, but since the outbreak of the epidemic this year, judging from the performance of emergency logistics, although the country's demand for solutions to public health emergencies has been largely realized, there are still operational gaps, which cannot be filled. The emergency logistics industry is still facing the problem of "large business volume, big talent gap, insufficient market supply, low staff capacity growth, which can't help emergency logistics enterprises better", through a reasonable combination of internal and external, to provide "the right number, satisfactory skills" of staff to the vacant positions. The ability to respond to public health emergencies with high demands on logistics, i.e. the supply chain management of emergency logistics personnel still has many problems, which are reflected in.

\subsubsection{Emergency Logistics Companies' Talent Planning Is Too Static and Too Long}

The characteristics of public health emergencies lie in their sudden occurrence, large scope of influence, and bad consequences, therefore, for the solution of public health emergencies, in this aspect of logistics, emergency logistics companies must be "fast, ruthless, and accurate". However, in the current situation, emergency logistics companies still show two major defects in talent planning, the first one is too static, and the second one is too long cycle.

\subsubsection{Emergency Logistics Companies Do Not Set up a Reasonable Training Management Platform for Talent Development}

Emergency logistics companies can enhance the ability of their employees by reasonably cultivating the existing incumbents, which is very beneficial for solving public health emergencies, but the current research situation shows that China's emergency logistics companies have not built a management platform and formulated a "talent reservoir" plan to help cultivate talents; they lack professional pre-service training. Professional skills training after employment cannot maximize the ROI of personnel training; there is no established and perfected motivation mechanism to bring incentive to employees and help emergency logistics enterprises to improve internal talent management mechanism, so as to maximize the assurance that the trained employees with professional skills can be retained (Zhang, 2016). 


\subsubsection{Emergency Logistics Companies Do Not Follow the Just in Time Principle Well in the Talent Supply Chain}

The idea of Just in Time was proposed by Toyota in the 1850s, and its basic idea is: to produce strictly on demand, to provide customers with the products they need at the time they need them, and the core idea is that enterprises can make quick adjustments to the rapidly changing market environment according to their own conditions.

However, many emergency logistics enterprises do not strictly implement the requirements of Just In Time and realize the talent supply chain of Just In Time, which is mainly reflected in the following: firstly, the talents needed by the employing department cannot be immediately allocated in place, and there are time delays; secondly, there are unneeded personnel in some departments within the enterprise, and there are even employees who do nothing; thirdly, the abilities shown by some employees do not match the abilities required by the position, resulting in the waste of talents.

\subsubsection{Lack of Flexibility in Talent Inventory Criteria for Emergency Logistics Companies}

The purpose of the talent inventory is to make enterprises better understand their own talent situation, so as to better realize the optimal allocation of human resources. But emergency logistics companies do not do their own enterprises have a very good understanding of the talent situation, talent inventory standards are too cumbersome, cannot do the talent inventory at any time, there is no way in the event of a public health emergency, to do a timely response to the high demand for logistics.

\subsection{Problems of Talent Security and Analysis of Causes}

The shortage of emergency logistics personnel in public health emergencies is magnified, and in addition to the problems in the supply chain analyzed above, there is also the problem of talent protection for emergency logistics companies. It is mainly divided into two directions: supply and demand.

From the supply point of view, in terms of talent recruitment, emergency logistics does not do a good job of strategic planning, only when there is a shortage of talent to start recruiting, which for responding to public health emergencies, cannot do a timely mobilization of personnel to solve the emergency. In the recruitment process, there is no reasonable examination system for the position ability, which can't help emergency logistics companies to screen out the right talents with the right ability, and the efficiency is not maximized in the subsequent pre-service training and on-the-job training (Ge, 2014).

From the demand point of view, emergency logistics enterprises have a greater need for competent personnel, because, in response to public emergencies, having qualified capabilities is the basic requirement for solving public health emergencies and inhibiting their adverse consequences from fermenting. However, at present, emergency logistics enterprises have not better policies and problem solving to protect talents, so the talent gap problem has not been well 
solved.

The causes of the above problems with talent security are analyzed as follows.

1) Difficulty in training talents

The main feature of public health emergencies is that they happen suddenly, have a wide range of impacts, and have adverse consequences. Therefore, when solving public health emergencies, the requirements for emergency logistics talents are relatively high. It is also difficult to train talents who can meet the public health emergencies in a short period of time, and it is difficult to achieve immediate results. Emergency logistics enterprises lack a reasonable plan on talent training, and fail to put more effort on pre-service training and on-the-job training to enhance the ability of talents. To do these tasks well, in addition to establishing a suitable training environment and atmosphere, it is also necessary to have professional training experts, but at present, the experts who train talents are generally expensive, few in number and time period, which is a big expense for emergency logistics enterprises.

2) Serious brain drain

At present, the country is not fully prepared to deal with public health emergencies, the ability of emergency logistics is not strong enough, the government policy is still in the process of improvement, emergency logistics enterprises are also in continuous development, employees cannot get a good sense of satisfaction at work, the identity of the work, the enterprise is not high enough, the management level of the emergency logistics enterprises themselves are still exploring the development of the talent management system. Insufficient perfection, so that people working in emergency logistics companies cannot predict good development prospects about themselves in their work, which can lead to a serious state of talent loss in emergency logistics companies.

3) Talent security policy is immature

Although the state has formulated some policies for emergency logistics enterprises in dealing with public health emergencies, the policies are still in a perfect state, especially in terms of talent introduction, talent training, talent planning, talent rewards, etc. It is difficult to provide a security system for the talents working in emergency logistics enterprises. Only when these policies are further developed and perfected, the problem of talent protection for emergency logistics enterprises can be solved.

\section{Recommendations for Supply Chain Management and Talent Assurance for Emergency Logistics Professionals in the Event of Public Health Emergencies}

\subsection{Recommendations for Supply Chain Management of Emergency Logistics Personnel in the Event of a Public Health Emergency}

\subsubsection{Talent Planning Should Be Scientific and Rational, and Shorten the Cycle}

Talent planning is the first step in talent supply chain management, and also one 
of the four major steps to optimize human resource management. Reasonable and scientific talent planning can help emergency logistics companies achieve their strategic development goals, and the development of short-cycle and flexible talent planning can achieve the requirement of providing emergency logistics enterprises with "a reasonable number of qualified and skilled" talents. Based on the special characteristics of emergency logistics companies, emergency logistics companies should always be prepared to meet the strong demand for emergency logistics brought about by public health emergencies that may occur at any time when making talent planning. Therefore, emergency logistics companies should develop a reasonable, short-cycle talent planning plan to help solve the problems caused by public health emergencies and national problems.

When doing talent planning for emergency logistics companies, not only should they incorporate strategies that are reasonably appropriate for current public health emergencies, but they should also take into account the unexpected nature of public health emergencies and prepare for future responses. Determine the future of emergency logistics companies to improve the number and skills of talent planning, and in the implementation process, to focus on the employees involved in talent planning, after the HR talent planning, so that the leadership of each department and employees are also involved, the leadership of each department for each employee's work status to make a suitable plan for each employee, so that the division of labor and cooperation in parallel talent planning development. This is the only way to better meet the flexible requirements of emergency logistics companies for talent planning (Deng et al., 2017).

\subsubsection{Focus on Emergency Logistics Personnel Training and Improve Employee Utilization Rate}

Talent training is one of the most important links in the talent supply chain management, but many enterprises do not establish a reasonable and perfect talent training management platform when training, and do not do in the daily training, training methods, training content and other aspects to consider the characteristics of the employees themselves, and negligence in the detection of the training effect, is not conducive to the maximum use of emergency logistics enterprise staff capabilities.

In order to maximize the use of staff capabilities, emergency logistics enterprises must do the following: First, shorten the pre-service training time and increase on-the-job training; second, establish and improve the talent selection system within the emergency logistics enterprises, set up a scientific and reasonable talent selection system for enterprises to select employees with appropriate abilities; third, reduce the number of people per training, increase the frequency of training to ensure that Emergency logistics companies have sufficient human resources at their disposal.

\subsubsection{Flexible Talent Inventory Criteria}

Talent inventory refers to the understanding of the overall talent situation in order to meet the needs of enterprises to be able to make good use of talent, and 
help companies make corresponding plan adjustments to meet the strategic development needs of enterprises. Therefore, emergency logistics companies need to make a standardized assessment tool, use the job skills matrix principle, standardize the job content, do a good job of module division and subdivision under the module, and do a good job of dividing each job level standardization principle, so as to be able to do the talent inventory. Flexibility is to achieve the need for emergency logistics companies to understand the talent situation and promote the development of emergency logistics companies.

\subsubsection{Talent Replenishment Based on Just in Time Principle}

In order to achieve the JIT, firstly, based on the changing external environment, it is necessary to accurately analyze the enterprise's external talent supply target, that is, to understand the enterprise's external talent demand degree in the current public health emergency and in the absence of a public health emergency. Secondly, we should reasonably select and evaluate the external talent suppliers of the counterpart emergency logistics enterprises, understand and evaluate the existing supplier channels, and expand more supplier channels. External suppliers of talent are considered during the evaluation phase, the negotiation and cooperation phase, and the inspection phase.

\subsection{Recommendations for Securing Emergency Logistics Personnel in Case of Public Health Emergencies}

\subsubsection{Increasing Talent Cultivation Efforts}

First of all, expand the direction of personnel training, personnel training in addition to the direction of on-the-job training, there is pre-service training, that is, university training. In addition to the cultivation of professional talents in the conceptual direction, we should also expand the cultivation of talents in professional ability; secondly, build an online network platform for talent training, and construct a perfect online network platform for talent training, which not only can expand the number of training groups more vigorously, but also can improve the training efficiency and solve the problem offline. Questions about training experts arise during training. Online participation in training can also make the talent can self-select the required acceptance of the ability of the training course, the class can be repeatedly listened to, and can raise their own issues directly on the Internet, on the Internet and training experts to communicate. In addition, emergency logistics companies should develop a corresponding system for the training platform, to develop a strict training audit system and training management system, to improve the efficiency of personnel training, emergency logistics to provide more qualified personnel with appropriate abilities.

\subsubsection{Broadening Talent Introduction Channels}

Talent introduction channels include not only key universities and domestic markets but also non-key universities and overseas markets. Emergency logistics enterprises should pay attention to and attract talents who study abroad, enhance the importance of overseas talents, formulate policies to attract overseas 
talents, and provide sufficient benefits and guarantees to the attracted talents in cooperation with the government, so as to bring new international ideas and new vitality to emergency logistics enterprises (Wang, 2007). In addition, in the introduction of talent, not only focus on the domestic key universities but also focus on non-key universities, can not only academic theory, cannot have prejudice to the talents from non-key universities, in fact, many non-key universities pay more attention to the talents in technology and ability training, the ability of its talents is also very good. Emergency logistics enterprises in the introduction of talent for different levels of talent, to establish a corresponding reasonable selection and management system, can not underestimate the introduction of non-key universities, to help improve the emergency logistics enterprise talent structure, to promote the solution of emergency logistics talent security.

\subsubsection{Improve Talent Security Policies}

Talent security problem must be solved inseparable from the policy support of the government and emergency logistics enterprises, in the development of talent security policy, we must first pay attention to the principles of policy system establishment, not only conducive to the development of talent, but also comprehensive, from all aspects of the factors that will have an impact on talent security, through a scientific and reasonable way to achieve the emergency logistics personnel supply, to solve the emergency logistics personnel security problem. Secondly, the establishment of emergency logistics personnel protection policy also needs to establish a complete framework system, to have an overall strategic awareness, in the introduction of talent, talent training, personnel incentives and other aspects of the development of corresponding policies to promote the talent protection efforts. Finally, after the development of a corresponding talent security policy, to implement into practice, to solve the problem of emergency logistics talent security, to reduce the impact of public health emergencies.

\section{Conclusion}

This paper analyzes the problems of talent supply chain management and talent security by studying the emergency logistics talent supply chain management and talent security under public health emergencies. The four problems of talent supply chain management are: first, talent planning is too static and the cycle is too long; second, a reasonable training management platform is not set for talent training; third, the talent replenishment cannot follow the Just in Time principle for replenishment; fourth, the talent inventory standard is not flexible enough. The problems of talent security are mainly from the supply and demand aspects. For talent supply chain management, four suggestions were made: first, talent planning should be scientific and reasonable, and shorten the talent planning cycle; second, focus on emergency logistics personnel training, improve employee utilization rate; third, talent inventory standards to be flexible; fourth, based on the principle of Just in Time, to achieve the talent supply. In view of the problem of talent security, three suggestions were made: first, increase the train- 
ing of talent; second, broaden the talent introduction channels; third, improve the talent security policy.

Due to the limited ability of the authors, the research on the supply chain management and talent security of emergency logistics under public health emergencies is not deep enough and can only start from the above directions, but in fact there are many other problems about talent supply chain management and talent security, and emergency logistics enterprises will also face many problems in the process of implementing the above recommendations in the future, which are subject to further discussion and research.

\section{Conflicts of Interest}

The authors declare no conflicts of interest regarding the publication of this paper.

\section{References}

Alfredo, M., Douglas, A., et al. (2016). Heuristic Approaches for the Multiperiod Location-Transportation Problem with Reuse of Vehicles in Emergency Logistics. Computers \& Operations Research, 69, 79-96. https://doi.org/10.1016/j.cor.2015.12.002

Chen, Y. (2017). Research on the Construction of Human Resource Supply Chain Management System of Pfizer Group. Master's Thesis, Changsha: Hunan University.

Chen, S. (2020). Research on Emergency Logistics in Infectious Disease Scenarios. Logistics Engineering and Management, 42, 103-104+81.

Chen, W., \& Hua, C. (2015). Research on Operation Models of Emergency Logistics Virtual Union Based on Emergency Lifecycle. Catastrophology, No. 2, 152-157.

Deng, W., Liu, K., Fang, J., \& Xu, J. (2017). Exploration and Practice of Talent Supply Chain Management in Large Coal Enterprises. Innovation Technology, No. 11, 49-54. https://www.doi.org/10.19345/j.cnki.1671-0037.2017.11.014

$\mathrm{Du}, \mathrm{P}$. (2016). Research on the Construction and Optimization of Emergency Logistics System in China. Master's Thesis, Lanzhou: Lanzhou University.

Dubey, S., Dahiya, M., et al. (2018). Application of Distributed Data Center in Logistics as Cloud Collaboration for handling Disaster Relief. 3rd International Conference on Internet of Things: Smart Innovation and Usages (pp. 1-11). 23-24 Feburuary 2018, Bhimtal. https://doi.org/10.1109/IoT-SIU.2018.8519865

Ge, K. (2014). Research on Demand for Highly Skilled Talents and Cultivation Guarantee System in Coal Enterprises. Beijing: China University of Mining and Technology.

Li, Y., Wu, H., \& Hou, H. (2017). Research on Navigation and Positioning Technology in the Field of Emergency Logistics. Global Positioning System, 42, 80-84.

Nachtmann, H., \& Pohl, E. A. (2013). Transportation Readiness Assessment and Valuation for Emergency Logistics. International Journal of Emergency Management, 9, 18-36. https://doi.org/10.1504/IJEM.2013.054099

Ou, Z., Wang, H., Jiang, D., Lu, B., Gan, W., \& Liang J. (2004). Emergency Logistics. Journal of Chongqing University (Natural Science Edition), No. 3, 164-167.

Wang, J. (2007). Strengths and Weaknesses of Talent Security in Caofeidian Industrial Zone and Talent Demand Prediction. Journal of Hebei University of Science and Technology (Social Science Edition), No. 4, 42-45+105. 
Xu, F. (2011). Talent Supply Chain Management Model. East China Economic Management, 25, 109-114+144.

Xue, H. (2015). Analysis of Mianyang City Government's Policy on Supporting the Development of Talent Guarantee for Science and Technology-based SMEs. Chengdu: University of Electronic Science and Technology.

Zhang, Y. (2016). Research on the Impact of Talent Supply Chain Management on Enterprise Performance. Wuhan: Hubei University. 